\title{
The use of dopamine-hyaluronate associate- coated maghemite nanoparticles to label cells
}

This article was published in the following Dove Press journal:

International Journal of Nanomedicine

14 March 2012

Number of times this article has been viewed

\section{Michal Babic ${ }^{1,2}$ \\ Daniel Horak ${ }^{1,2}$ \\ Pavla Jendelova ${ }^{2,3}$ \\ Vit Herynek ${ }^{2,4}$ \\ Vladimir Proks ${ }^{1,2}$ \\ Vaclav Vanecek, ${ }^{2,3}$ \\ Petr Lesny ${ }^{2,3}$ \\ Eva Sykova ${ }^{2,3}$}

'Institute of Macromolecular Chemistry, Academy of Sciences of the Czech Republic, Heyrovsky Sq 2, ${ }^{2}$ Center for Cell Therapy and Tissue Repair, Charles University, V Uvalu 84, ${ }^{3}$ Institute of Experimental Medicine, Academy of Sciences of the Czech Republic, Videnska I083, ${ }^{4}$ Institute for Clinical and Experimental Medicine, Videnska 1958, Prague, Czech Republic

Correspondence: Daniel Horak Institute of Macromolecular Chemistry, Academy of Sciences of the Czech Republic, Heyrovsky Sq 2, 16206 Prague 6, Czech Republic Tel +420296809260

Fax +420296809 410

Email horak@imc.cas.cz

\begin{abstract}
Sodium hyaluronate (HA) was associated with dopamine (DPA) and introduced as a coating for maghemite $\left(\gamma-\mathrm{Fe}_{2} \mathrm{O}_{3}\right)$ nanoparticles obtained by the coprecipitation of iron(II) and iron(III) chlorides and oxidation with sodium hypochlorite. The effects of the DPA anchorage of HA on the $\gamma-\mathrm{Fe}_{2} \mathrm{O}_{3}$ surface on the physicochemical properties of the resulting colloids were investigated. Nanoparticles coated at three different DPA-HA $\gamma-\mathrm{Fe}_{2} \mathrm{O}_{3}$ and DPA/HA ratios were chosen for experiments with rat bone marrow mesenchymal stem cells and human chondrocytes. The nanoparticles were internalized into rat bone marrow mesenchymal stem cells via endocytosis as confirmed by Prussian Blue staining. The efficiency of mesenchymal stem cell labeling was analyzed. From among the investigated samples, efficient cell labeling was achieved by using DPA-HA- $\gamma-\mathrm{Fe}_{2} \mathrm{O}_{3}$ nanoparticles with DPA-HA/ $\gamma$ - $\mathrm{Fe}_{2} \mathrm{O}_{3}=0.45$ (weight/ weight) and DPA/HA $=0.038$ (weight/weight) ratios. The particles were used as a contrast agent in magnetic resonance imaging for the labeling and visualization of cells.
\end{abstract}

Keywords: nanoparticles, dopamine, hyaluronate, cell labeling, magnetic

\section{Introduction}

Magnetic nanoparticles and nanowires are currently utilized in a wide variety of medical diagnostic and therapeutic applications such as hyperthermia, cell sorting, cell tracking and tissue engineering, ${ }^{1}$ as contrast agents for magnetic resonance imaging (MRI), and for the manipulation and spatial organization of cells. ${ }^{2}$ Cell labeling with magnetic nanoparticles is an increasingly common method for cell separation as well as for the repeated noninvasive monitoring of the migration and distribution of transplanted cells in the host tissue by MRI. ${ }^{3}$

As water in the tissue contains most of the protons, MRI in fact detects the distribution of tissue water. However, MRI contrast can also be weighted by different physical properties of the detected water molecules, the most important of which are the so-called relaxation times $\mathrm{T}_{1}, \mathrm{~T}_{2}$, or $\mathrm{T}_{2}{ }^{*}$, thus even native MRI (without the application of contrast agents) provides valuable information about the tissue. However, the resolution of MRI is too low to detect single cells, therefore it is necessary to label transplanted cells with a suitable contrast agent to enable their subsequent detection using MRI. Although MRI does not detect the contrast agent itself, contrast agents considerably alter the relaxation times of water in their vicinity and thus influence the contrast of the images. As a result, the size of the area impacted by a contrast agent is considerably larger than the size of the contrast agent - or the size of the labeled cell - itself. Superparamagnetic nanoparticles create local inhomogeneities in a static field leading to the considerable shortening of $\mathrm{T}_{2}$ and $\mathrm{T}_{2}{ }^{*}$ relaxation times and rapid signal loss. 
Their presence is therefore manifested by hypointense areas in a $\mathrm{T}_{2}$-weighted or $\mathrm{T}_{2}{ }^{*}$-weighted MRI.

Magnetic cell labeling could also aid cell-based therapies by directing stem cells to diseased locations ${ }^{4}$ and providing cell-based carriers to transport therapeutic genes to tumors. ${ }^{5}$ Iron oxide nanoparticles, especially maghemite $\left(\gamma-\mathrm{Fe}_{2} \mathrm{O}_{3}\right)$ ones, are the most suitable magnetic material because of their biocompatibility and their superparamagnetic properties. Iron oxide contained in endosomes and lysosomes is metabolized into elemental iron by hydrolytic enzymes. ${ }^{6}$ The advantage of iron is that the human body is designed to process excess iron, and it is stored mainly in the protein ferritin. For most in vivo applications, the efficient internalization of nanoparticles into specific cells requires the minimization of undesired biological interactions such as nonspecific targeting (plasma protein adsorption) and short blood lifespan due to opsonization, which induces the removal of the particles by the reticuloendothelial system. To achieve the efficient and specific cellular uptake of magnetic nanoparticles requires the nanoparticle surface to be modified with suitable ligands or transfection agents, which also enhances colloid stability and cell interactions. Surface modifications can also be used to minimize toxicity. Modifications of neat or dextran-coated iron oxide with human immunodeficiency virus-Tat peptide, ${ }^{7,8}$ dendrimers, ${ }^{9}$ lipofection agents, ${ }^{10,11}$ poly(L-lysine), ${ }^{12-14}$ and carboxymethyl chitosan ${ }^{15}$ have recently been reported.

Hyaluronate (HA), a naturally occurring polysaccharide consisting of $\beta$-1,3- $N$-acetylglucosaminyl- $\beta$-1,4-glucuronide and having a molecular weight ranging from $1-10,000 \mathrm{kDa}$, is an abundant component of the extracellular matrix, ${ }^{16}$ the synovial fluid, and connective, epithelial, and neural tissues. ${ }^{17}$ As a result of its ability to form hydrated expanded matrices, HA has often been used in cosmetic applications such as soft tissue augmentation. Moreover, in various studies HA has been utilized as a targeting ligand directed at cancer cells. ${ }^{18,19}$ At the same time, HA-immobilized iron oxide nanoparticles allow tumor tissue imaging. The advantage of HA for clinical applications is that it is biocompatible, antigenic, and negatively charged, thus forming ionic bonds with positively charged proteins to increase its affinity towards cells. The disadvantage of HA lies in its rapid resorption ${ }^{20,21}$ unless it is crosslinked or chemically modified. HA interacts with HA receptors such as CD44, RHAMM, and ICAM-1, which triggers intracellular signals influencing cellular proliferation, differentiation, and migration. ${ }^{18}$

The aim of the present work was to explore the potential usefulness of dopamine (DPA) as an agent to anchor HA to the iron oxide surface, using different DPA/HA ratios in the formation of a biomimetic shell. The second aim was to investigate the effect of a DPA-HA coating on iron oxide nanoparticles in terms of cell behavior, internalization, and differentiation, which could contribute to a better understanding of cell-biomaterial interactions. The pivotal role of anchoring a DPA-HA conjugate on the nanoparticle surface via bioinspired adhesion in MRI and cellular uptake was already described by Lee et al. ${ }^{18} \mathrm{~A}$ key feature of DPA is the ortho-dihydroxyphenyl (catechol) functional group in planar ordering, which forms strong bonds with various inorganic (including transition metals)/organic surfaces that were shown to be stronger than biotin-streptavidin interactions. ${ }^{22}$ In contrast to Lee et al, ${ }^{18}$ who synthesized magnetic nanocrystals by the thermal decomposition of an iron oleate complex, which required their transfer to water using cetyltrimethylammonium bromide, the new approach in the present study uses $\gamma-\mathrm{Fe}_{2} \mathrm{O}_{3}$ nanoparticles prepared by a coprecipitation method in water and subsequent coating with a DPA-HA associate.

\section{Material and methods Materials}

Iron(II) chloride tetrahydrate $\left(\mathrm{FeCl}_{2} \cdot 4 \mathrm{H}_{2} \mathrm{O}\right)$ and iron(III) chloride hexahydrate $\left(\mathrm{FeCl}_{3} \cdot 6 \mathrm{H}_{2} \mathrm{O}\right)$ were purchased from Fluka (Buchs, Switzerland), sodium hypochlorite solution $(\mathrm{NaClO})$ from Bochemie (Bohumin, Czech Republic), and sodium citrate dihydrate from Lachema (Brno, Czech Republic). Sodium HA (molecular weight: 300,000) was obtained from Contipro Pharma (Dolni Dobrouc, Czech Republic), DPA hydrochloride and $\mathrm{N}$-(3dimethylaminopropyl)- $N$-ethylcarbodiimide hydrochloride from Sigma-Aldrich Corporation (St Louis, MO), and the commercial contrast agent Endorem ${ }^{\circledR}$ from Guerbet (Roissy, France). Ultrapure Q-water ultrafiltered on a Milli- $\mathrm{Q}^{\circledR}$ Gradient A $10^{\circledR}$ system (Millipore SAS, Molsheim, France) was used throughout the work. All other reagent grade chemicals were purchased from Sigma-Aldrich and used as received. For histological staining, potassium ferrocyanide (Lachema) and Alcian Blue (Sigma-Aldrich) were used. Phosphate buffered saline (PBS) was from Sigma-Aldrich.

\section{Association of HA with DPA}

In a typical experiment, $\mathrm{HA}(0.402 \mathrm{~g} ; 1 \mathrm{mmol})$ was dissolved in $30 \mathrm{~mL}$ of Q-water and the solution purged with nitrogen prior to the addition of $\mathrm{N}$-(3-dimethylaminopropyl)$N^{\prime}$-ethylcarbodiimide hydrochloride $(19 \mathrm{mg} ; 0.1 \mathrm{mmol})$ and DPA (19 mg; $0.1 \mathrm{mmol}$ ). The mixture was adjusted to $\mathrm{pH} 5$ by the addition of $1 \mathrm{M}$ hydrochloric acid and then the 
reaction proceeded in darkness for 12 hours at laboratory temperature with stirring under a nitrogen atmosphere. As the resulting mixture was colorless, DPA was not oxidized during the reaction. The DPA-HA associate was separated and purified by double precipitation in an excess of acetone. The precipitate was then dissolved in Q-water and freeze-dried.

\section{Synthesis of $\gamma-\mathrm{Fe}_{2} \mathrm{O}_{3}$ nanoparticles}

A solution of iron(II) chloride $(0.2 \mathrm{~mol} / \mathrm{L})$ and iron(III) chloride $(0.2 \mathrm{~mol} / \mathrm{L})$ in a $1: 2$ molar ratio was coprecipitated in an excess of $0.5 \mathrm{M}$ ammonium hydroxide by a procedure described earlier. ${ }^{23}$ After 15 minutes, the product was repeatedly separated in a magnetic field and washed with Q-water to reach peptization. The colloid was subsequently sonicated for 5 minutes (Ultrasonic Homogenizer 4710 series; Cole-Parmer Instruments, Vernon Hills, IL; $40 \%$ output) and oxidized with 5 weight percent sodium hypochlorite aqueous solution in the presence of $0.1 \mathrm{M}$ sodium citrate solution. The washing and sonication procedures were then repeated. The resulting colloid was filtered through a cellulose nitrate membrane filter with $0.45 \mu \mathrm{m}$ pores. The colloid contained typically $\sim 40 \mathrm{mg} \gamma-\mathrm{Fe}_{2} \mathrm{O}_{3} / \mathrm{mL}$ as estimated by weight analysis.

\section{Coating of $\gamma-\mathrm{Fe}_{2} \mathrm{O}_{3}$ nanoparticles with DPA-HA associate}

A water solution $(0.5,1$, or $2 \mathrm{~mL})$ of lyophilized DPA-HA $(10 \mathrm{mg} / \mathrm{mL})$ was passed through a syringe filter with a cellulose nitrate membrane $(0.22 \mu \mathrm{m}$ pores $)$ and diluted with Q-water. Neat $\gamma-\mathrm{Fe}_{2} \mathrm{O}_{3}$ colloid ( $\sim \mathrm{mL}$; $44 \mathrm{mg}$ of dry $\gamma-\mathrm{Fe}_{2} \mathrm{O}_{3}$ ) was added to the diluted DPA-HA solution, the total volume was adjusted to $10 \mathrm{~mL}$, and the mixture was sonicated for 5 minutes. Coating with neat DPA and HA was done as a control.

\section{Characterization of the nanoparticles}

The hydrodynamic diameter $\left(\mathrm{D}_{\mathrm{h}}\right)$, polydispersity $(\mathrm{PI})$, and zeta potential were determined by dynamic light scattering with an Autosizer Lo-C ${ }^{\circledR}$ (Malvern Instruments, Malvern, United Kingdom). pH was measured on a pH meter (211; Hanna Instruments, Smithfield, RI) equipped with an Orion 9802BN micro-combination $\mathrm{pH}$ electrode (Balcatta, Australia). Particle morphology, particle size, and the particle size distribution were examined by a Spirit $\mathrm{G}^{2}$ Tecnai $^{\mathrm{TM}}$ transmission electron microscope (TEM; FEI, Brno, Czech Republic) by measuring at least 300 particles for each sample. The particle size distribution was characterized by the polydispersity index (PDI), calculated as the ratio of weight-average to number-average particle diameter. Elemental analysis was performed on a PerkinElmer 2400 CHN apparatus (PerkinElmer, Waltham, MA). Size exclusion chromatography was performed on a KNAUER Smartline 1000 system (KNAUER, Berlin, Germany) with a PDA Smartline 2800 detector and Alltech ${ }^{\circledR} 3300$ evaporative light scattering detector (Grace Davison Discovery Sciences, Deerfield, IL). Measurements were carried out on a TSKgel G6000PW column (Tosoh Bioscience GmbH, Stuttgart, Germany) using $0.3 \mathrm{M}$ ammonium acetate buffer as an isocratic eluent.

\section{Cell cultures}

To isolate rat bone marrow mesenchymal stem cells (MSCs), femurs were dissected from 4-week-old Wistar rats. The ends of the bones were cut, and the marrow extruded with $5 \mathrm{~mL}$ of Dulbecco's Modified Eagle's Medium (DMEM) with L-glutamine (PAA Laboratories GmbH, Pasching, Austria) using a needle and syringe. Marrow cells were plated in $80-\mathrm{cm}^{2}$ tissue culture flasks in DMEM/10\% fetal bovine serum with $100 \mathrm{U} / \mathrm{mL}$ penicillin and $0.1 \mathrm{mg} / \mathrm{mL}$ streptomycin. After 24 hours, the nonadherent cells were removed by replacing the medium. The medium was changed every 2-3 days as the cells grew to confluence. The cells were lifted by incubation with 0.25 weight percent trypsin solution.

As a second model, human chondrocytes isolated from human cartilage were used. Human chondrocytes were obtained from meniscal biopsies of the knee joint. Meniscal fragments were minced, washed with PBS, and digested in $0.25 \%$ trypsin-ethylenediaminetetraacetic acid (Invitrogen Life Technologies, Paisley, United Kingdom) for 1 hour and subsequently in $0.25 \%$ collagenase type I in DMEM/ F12 medium overnight. Recovered cells were washed with PBS and plated in a $75-\mathrm{cm}^{2}$ tissue culture flask in DMEM/ F12 medium containing 10\% fetal bovine serum, $100 \mathrm{U} / \mathrm{mL}$ penicillin, and $0.1 \mathrm{mg} / \mathrm{mL}$ streptomycin.

\section{Cell labeling, cell growth, and cell viability}

Rat MSCs and human chondrocytes, 100,000 cells/mL media, were cultured in a twelve-well culture dish, and a colloid containing $15.4 \mu \mathrm{g}$ of iron per $\mathrm{mL}$ of $\mathrm{DPA}-\gamma-\mathrm{Fe}_{2} \mathrm{O}_{3}$, $\mathrm{HA}-\gamma-\mathrm{Fe}_{2} \mathrm{O}_{3}$, DPA-HA- $\gamma-\mathrm{Fe}_{2} \mathrm{O}_{3}$, or Endorem was added; the incubation lasted for 48 hours. The nanoparticles were washed out using PBS and then the cells were harvested by trypsin-ethylenediaminetetraacetic acid and counted. The mean numbers of unlabeled cells were taken as $100 \%$, and the mean numbers of labeled cells were expressed as percentages 
relative to the $100 \%$ control. All experiments were done in triplicate and performed on cells from three different cultures. The viability of rat MSCs and human chondrocytes was determined using the trypan blue ( 0.1 weight percent) exclusion test.

\section{Labeling efficiency and staining intensity}

The iron oxide-labeled cells were fixed in $4 \%$ paraformaldehyde in $0.1 \mathrm{M}$ phosphate buffer ( $\mathrm{pH}$ 7.4) for 30 minutes, washed, and stained for iron to produce ferric ferrocyanide (Prussian Blue). Nuclei were counterstained with nuclear fast red (Sigma-Aldrich). Labeling efficiency was determined by manually counting the number of Prussian Blue-stained and unstained cells in five optical fields from each plate using an Axioplan ${ }^{\circledR}$ Imaging II microscope at $100 \times$ magnification and a $10 \times / 0.75$ objective lens, an AxioCam ${ }^{\circledR}$ digital camera, and AxioVision ${ }^{\circledR} 4$ software (Carl Zeiss AG, Oberkochen, Germany). The intensity of Prussian Blue-stained cells was measured colorimetrically. The scanned images with manually labeled cells were processed by the MATLAB ${ }^{\circledR}$ 6.0 Image Processing Toolbox ${ }^{\mathrm{TM}}$ (MathWorks, Natick, MA). Before the analysis, the colorimetric scale from the image colors corresponding to the increasing intensities of the Prussian Blue staining of the cells was validated. Each Prussian Blue-stained cell in the image was then processed and the intensity of the cytoplasmic staining determined as the intensity of the color of the cytoplasm on the scale. As a result, two parameters were obtained: (1) the presence or absence of a label inside the cells expressed as the percentage of labeled cells and (2) the amount of label inside the cells, which correlates with the intensity of the staining.

\section{Cell differentiation}

Rat MSCs were labeled with $\mathrm{HA}-\gamma-\mathrm{Fe}_{2} \mathrm{O}_{3}$ and DPA-HA- $\gamma-\mathrm{Fe}_{2} \mathrm{O}_{3}$ nanoparticles or the commercial contrast agent Endorem. The cells were incubated with the nanoparticles at a concentration of $15.4 \mu \mathrm{g}$ iron $/ \mathrm{mL}$ media. After 72 hours of incubation, the contrast agents were washed out by removing the medium and rinsing the cell monolayer three times with PBS.

To induce chondrogenesis, the labeled cells were harvested, transferred to polypropylene tubes, and differentiated in pellet cultures $(250,000$ cells/pellet $)$ in freshly prepared serum-free medium containing DMEM, $0.1 \mu \mathrm{M}$ dexamethasone (SigmaAldrich), hTGF- $\beta 1$ (10 ng/mL; Millipore Corporation, Billerica, MA), $0.05 \mathrm{mM}$ L-ascorbic acid (Sigma-Aldrich), 1\% ITS+ Universal Culture Supplement (BD Biosciences, San Jose, CA) and Primocin ${ }^{\mathrm{TM}}(100 \mu \mathrm{g} / \mathrm{mL}$; Lonza Cologne $\mathrm{GmbH}$, Cologne, Germany). The tubes were incubated at $37^{\circ} \mathrm{C}$ in $5 \%$ carbon dioxide. The medium was changed twice a week. Chondrogenic pellets were harvested after 20 days in culture, fixed with $4 \%$ paraformaldehyde, embedded in paraffin blocks, cut into $5 \mu \mathrm{m}$ sections, and stained with Alcian Blue and Prussian Blue using standard methods.

\section{MRI relaxometry}

MRI relaxometry of the coated $\gamma-\mathrm{Fe}_{2} \mathrm{O}_{3}$ nanoparticles was performed using a Minispec ${ }^{\circledR} 0.5 \mathrm{~T}$ relaxometer (Bruker Optik GmbH, Ettlingen, Germany). HA- $\gamma-\mathrm{Fe}_{2} \mathrm{O}_{3}$ or DPA$\mathrm{HA}-\gamma-\mathrm{Fe}_{2} \mathrm{O}_{3}$ colloids were diluted to final concentrations of $0.022 \mathrm{mg}$ iron $/ \mathrm{mL}$ and sonicated for 10 minutes prior to the measurement. $\mathrm{T}_{2}$ relaxometry was performed with a Carr-Purcell-Meiboom-Gill multispin-echo sequence with an echo spacing of 2 milliseconds and repetition time of 5 seconds. The measured relaxation times were converted to relaxivities (reciprocal values of relaxation times $\mathrm{T}_{2}$ related to concentration, ie, relaxivity $=1 / \mathrm{T}_{2}$ /concentration).

Phantoms containing suspensions of fixed labeled cells were prepared by dispersing the suspensions in gelatin to eliminate sedimentation of the cells on the bottom of the test tube, then measured at $0.5 \mathrm{~T}$ (Minispec $0.5 \mathrm{~T}$ relaxometer; Bruker) and at $4.7 \mathrm{~T}$ (BioSpec ${ }^{\circledR} 4.7 \mathrm{~T}$ spectrometer; Bruker). $\mathrm{T}_{2}$ relaxation times at $0.5 \mathrm{~T}$ were measured with the same sequence and parameters as stated above. At $4.7 \mathrm{~T}$, a Carr-Purcell-Meiboom-Gill multispin-echo sequence with an echo spacing of 8.63 milliseconds and repetition time of 5 seconds was used. The sequence provided a set of $\mathrm{T}_{2}$-weighted images (with increasing weighting), from which $\mathrm{T}_{2}$ relaxation times were calculated. Relaxation rates were calculated as the reciprocal values of relaxation times related to one million cells per $1 \mathrm{~mL}$.

As superparamagnetic nanoparticles have a markedly smaller effect on $\mathrm{T}_{1}$ and are used solely as a $\mathrm{T}_{2}$ contrast agent, $\mathrm{T}_{1}$ of the nanoparticles was not measured.

\section{Results and discussion}

$\gamma-\mathrm{Fe}_{2} \mathrm{O}_{3}$ was selected as the most stable iron oxide. $\gamma-\mathrm{Fe}_{2} \mathrm{O}_{3}$ nanoparticles were obtained by the coprecipitation of iron(II) and iron(III) chlorides in ammonium hydroxide, and the resulting magnetite $\left(\mathrm{FeO} \cdot \mathrm{Fe}_{2} \mathrm{O}_{3}\right)$ was oxidized to $\gamma-\mathrm{Fe}_{2} \mathrm{O}_{3}$ with sodium hypochlorite. The Mossbauer spectra published previously confirmed that the iron oxide constituting the nanoparticles was predominantly $\gamma-\mathrm{Fe}_{2} \mathrm{O}_{3} \cdot{ }^{24} \mathrm{TEM}$ was used to determine the shape, size, and uniformity of the dried nanoparticles. TEM analysis indicated that uncoated $\gamma-\mathrm{Fe}_{2} \mathrm{O}_{3}$ particles showed a rather narrow size distribution $(\mathrm{PDI}=1.30)$ with an average size of the nanoparticles of 

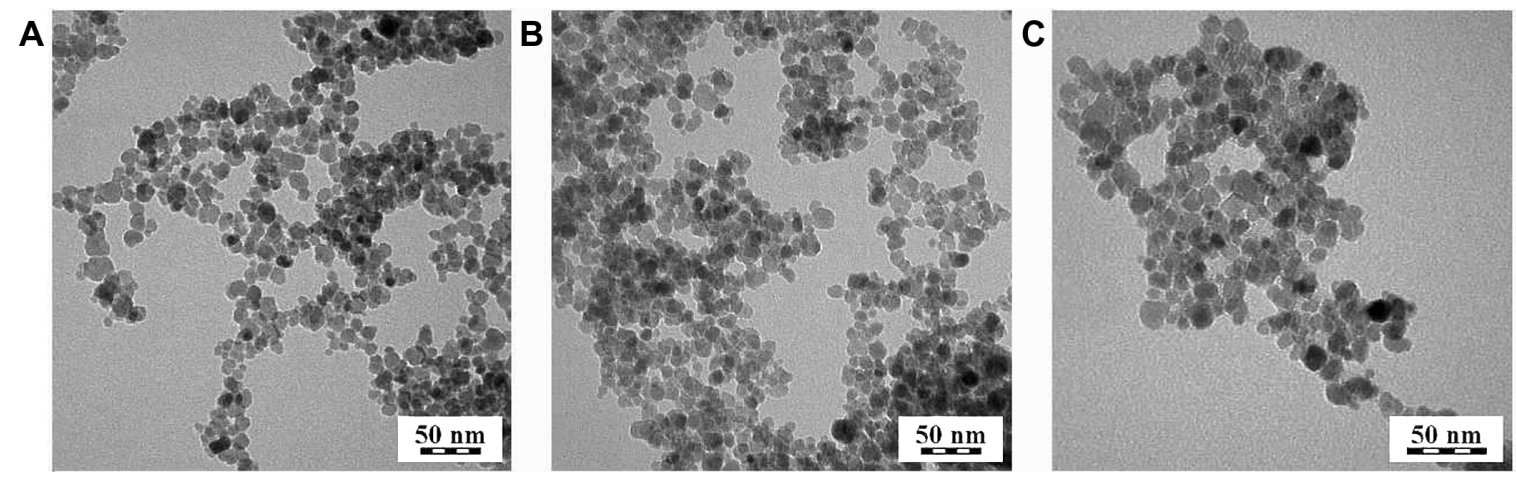

Figure I Transmission electron micrograph of $(\mathbf{A})$ neat maghemite and dopamine-hyaluronate-maghemite nanoparticles, $(\mathbf{B})$ Run IIIA/I (dopamine-hyaluronate/maghemite = 0.1 I weight/weight; dopamine/hyaluronate $=0.0075$ weight $/$ weight), and $(\mathbf{C})$ Run IIIA $/ 3$ (dopamine-hyaluronate/maghemite $=0.3$ weight $/$ weight; dopamine $/$ hyaluronate $=$ 0.0075 weight/weight).

$10.7 \mathrm{~nm}$ (Figure 1A). The $\mathrm{D}_{\mathrm{h}}$ and zeta potential of colloidal $\gamma-\mathrm{Fe}_{2} \mathrm{O}_{3}$ were estimated using dynamic light scattering at $\mathrm{pH}$ $\sim 8$. $\mathrm{D}_{\mathrm{h}}$ was $83.7 \pm 0.6 \mathrm{~nm}$ and PI was $0.129 \pm 0.006$, confirming the above-mentioned relatively narrow size distribution, and the zeta potential reached $-53.4 \pm 0.8 \mathrm{mV}$, reflecting good colloidal stability. The difference in particle size measured with TEM and dynamic light scattering can be ascribed to the dynamic fluctuations of colloidal nanoparticles in comparison with the dried state and also to the different statistical methods used in the two kinds of measurements.

\section{Modification of HA}

In an attempt to obtain a DPA-HA associate, conventional $\mathrm{N}$-(3dimethylaminopropyl)- $N$ '-ethylcarbodiimide hydrochloride/ DPA chemistry was investigated in an HA (molecular weight: $\sim 300,000$ ) solution at ten different $\mathrm{pH}$ values ranging from 5-10. A small amount of sodium metabisulfite $\left(\mathrm{Na}_{2} \mathrm{~S}_{2} \mathrm{O}_{5}\right)$ was added to avoid the irreversible oxidation of DPA. Coupling was also studied with dicyclohexylcarbodiimide and diisopropylcarbodiimide; both agents were combined with a $N$-hydroxysuccinimide in a water/ $N, N$-dimethylformamide, (1/3 volume/volume) mixture. Another technique using $N, N, N^{\prime}, N^{\prime}$-tetramethyl-O-(N-succinimidyl)uronium hexafluorophosphate was tested as well. However, the formation of a covalent bond between HA and DPA was never confirmed by size exclusion chromatography (Figure 2). In the chromatogram, the main signal recorded by the diode array detection ultraviolet detector $(256 \mathrm{~nm})$ was that of DPA (elution time 13 minutes), while signals in the area of high molecular weight compounds were absent. Signals recorded by the evaporative light scattering detector at elution times of 2.5, 5 , and 9 minutes typical for high molecular weight compounds were ascribed to HA. This is contrary to information from reports in which the formation of a covalent bond between
HA and DPA was assumed according to nuclear magnetic resonance spectra. ${ }^{18,25,26}$ Carbodiimides, thus, were not found to be suitable coupling agents to covalently attach DPA to HA. Nevertheless, the reaction between the amine groups of DPA and the carboxyl groups of HA yielded an ionic associate (Figure 3) as confirmed by elemental analysis; compared with HA, nitrogen content was increased in the DPA-HA associate (Table 1).

\section{Coating of $\gamma-\mathrm{Fe}_{2} \mathrm{O}_{3}$ nanoparticles with DPA, HA, and DPA-HA associate}

Modifying the surface of iron oxide nanoparticles is a common strategy to enhance the cellular uptake of nanoparticles.

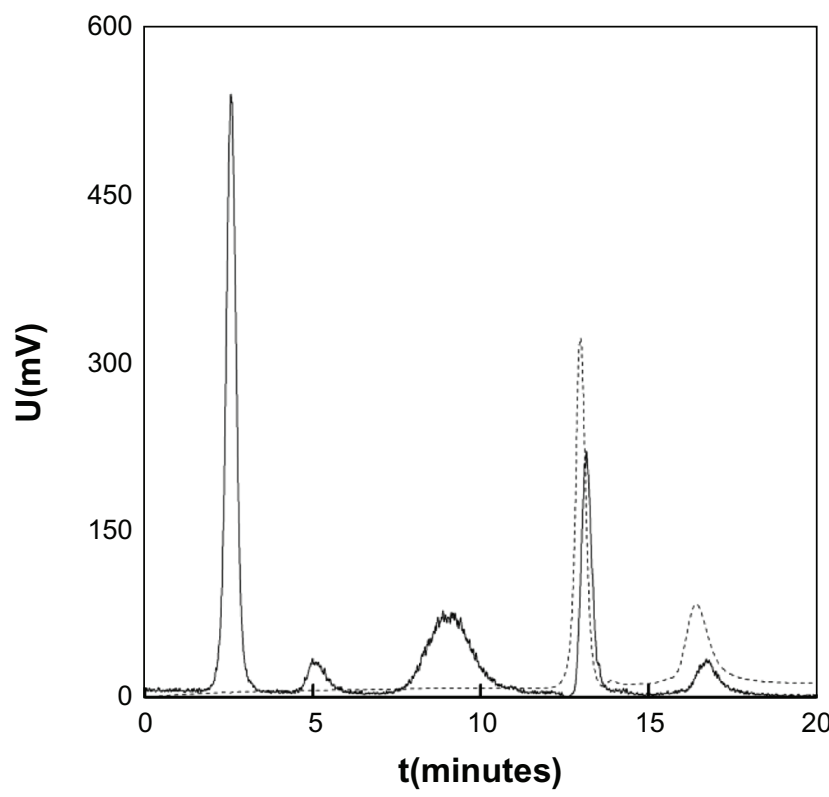

Figure 2 Size-exclusion chromatogram of dopamine-hyaluronate in $0.3 \mathrm{M}$ ammonium acetate buffer ( $\mathrm{pH}$ 6.5). Evaporative light scattering detection (solid line) and diode array detection at $256 \mathrm{~nm}$ (dashed line).

Abbreviations: $t$, time; $U$, voltage. 


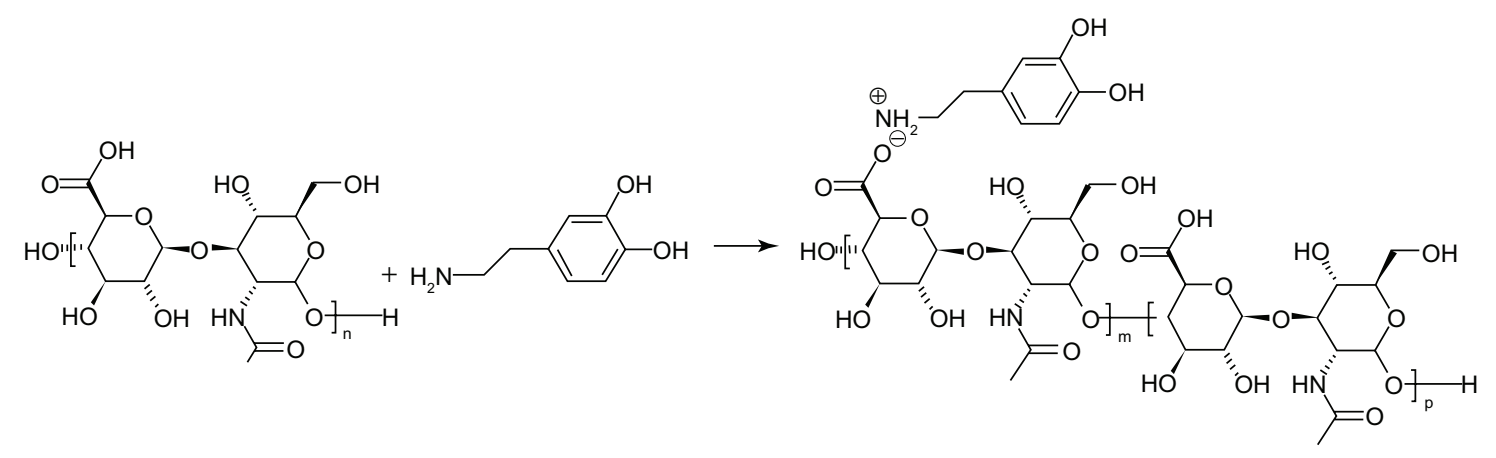

Figure 3 Association of hyaluronate with dopamine.

In the present study, HA was intentionally included as a modifying agent to provide a protective shell preventing particle aggregation, while bidentate DPA should serve as an anchoring moiety. It is an advantage of DPA that the catechol derivatives tightly bind onto the surface of iron oxide particles, ${ }^{27}$ resulting in the formation of DPA- $\gamma-\mathrm{Fe}_{2} \mathrm{O}_{3}$ complexes. In contrast, HA does not show such a strong interaction with $\gamma-\mathrm{Fe}_{2} \mathrm{O}_{3}$. The reactive amino groups of DPA can then act as coupling links for further association with modifying or cell targeting agents. ${ }^{28} \mathrm{In}$ this report, an ionic DPA-HA associate was first prepared and added to $\gamma-\mathrm{Fe}_{2} \mathrm{O}_{3}$ nanoparticles, with DPA being attached to iron oxide via hydroxyl groups, ${ }^{29}$ while amino groups associated $\mathrm{HA}$ (Figure 3). According to TEM, the size of the DPA-HA- $\gamma-\mathrm{Fe}_{2} \mathrm{O}_{3}$ particles was between 7.6-9.5 nm (Figure 1B and C), ie, almost the same as that of neat particles. The PDI was $1.26-1.34$, which is in accordance with the PDI of neat particles.

Several groups of DPA- $\gamma-\mathrm{Fe}_{2} \mathrm{O}_{3}, \mathrm{HA}-\gamma-\mathrm{Fe}_{2} \mathrm{O}_{3}$, and DPA$\mathrm{HA}-\gamma-\mathrm{Fe}_{2} \mathrm{O}_{3}$ nanoparticles were prepared differing in their composition (Table 2). Coatings by neat DPA (Group I) or neat HA (Group II) were used as controls and compared with DPA-HA- $\gamma-\mathrm{Fe}_{2} \mathrm{O}_{3}$ nanoparticles (Group III) prepared at three different DPA/HA ratios; they were denoted as IIIA-C (Table 2). In each group, three samples with a constant concentration of $\gamma-\mathrm{Fe}_{2} \mathrm{O}_{3}$ and an increasing concentration of DPA-HA associate (or neat DPA or HA) were prepared (Table 2). Four parameters were measured as functions of the DPA $/ \gamma-\mathrm{Fe}_{2} \mathrm{O}_{3}, \mathrm{HA} / \gamma-\mathrm{Fe}_{2} \mathrm{O}_{3}$, and DPA- $\mathrm{HA} / \gamma-\mathrm{Fe}_{2} \mathrm{O}_{3}$ mass ratios: $\mathrm{D}_{\mathrm{h}}, \mathrm{PDI}$, zeta potential, and $\mathrm{pH}$.

Table I Elemental analysis of hyaluronate and dopaminehyaluronate associate

\begin{tabular}{lllll}
\hline Elemental analysis (wt\%) & $\mathbf{C}$ & $\mathbf{H}$ & $\mathbf{N}$ & $\mathbf{N a}$ \\
\hline HA & 39.82 & 5.30 & 3.19 & 6.43 \\
DPA-HA associate & 39.82 & 5.79 & 3.85 & 2.67 \\
\hline
\end{tabular}

Abbreviations: $\mathrm{C}$, carbon; DPA, dopamine; $\mathrm{H}$, hydrogen; $\mathrm{HA}$, hyaluronate; $\mathrm{N}$, nitrogen; $\mathrm{Na}$, sodium; wt\%, weight percent.
With an increasing $\mathrm{HA} / \gamma-\mathrm{Fe}_{2} \mathrm{O}_{3}$ or DPA- $\mathrm{HA} / \gamma-\mathrm{Fe}_{2} \mathrm{O}_{3}$ ratio, the $\mathrm{D}_{\mathrm{h}}$ and PDI increased, probably due to the thicker shell; at the same time, the zeta potential and $\mathrm{pH}$ decreased (Table 2). The zeta potential is an indicator of the colloidal stability of magnetic nanoparticles in an aqueous medium. The high negative electric charge on the surface of the HA- $\gamma-\mathrm{Fe}_{2} \mathrm{O}_{3}$ nanoparticles (Runs I/1, I/2, II/1-3, and III) possessing a zeta potential in the range between $-48 \mathrm{mV}$ and $-79 \mathrm{mV}$ prevented their aggregation in water due to the repulsion among the particles. This negative charge was provided by the ionized carboxylic groups of HA, ensuring the colloidal stability of the HA- $\gamma-\mathrm{Fe}_{2} \mathrm{O}_{3}$ and DPA-HA- $\gamma-\mathrm{Fe}_{2} \mathrm{O}_{3}$ dispersions. At a high DPA $\gamma-\mathrm{Fe}_{2} \mathrm{O}_{3}$ ratio (Run $\mathrm{I} / 3$ ), the zeta potential already approached zero $(-7 \mathrm{mV})$ due to the positive charge of the large amounts of DPA; as a result, colloidal stability was lost. Aggregation was also observed with DPA-HA- $\gamma-\mathrm{Fe}_{2} \mathrm{O}_{3}$ particles Run IIIC/3, characterized by a high DPA content in the DPA-HA associate. This was probably due to the relatively high zeta potential of the discrete particles (Run I/3, Table 2) caused by the fast complexation of small positively-charged DPA molecules to their surface. In contrast, bulky negatively-charged HA was exposed on the surface of particle aggregates, thus inducing the high negative charge of DPA-HA- $\gamma-\mathrm{Fe}_{2} \mathrm{O}_{3}$ Run IIIC/3 (-78 mV; Table 2). The particle size decreased in the sequence III/A $>$ III/B $>$ III/C; in the same sequence DPA/HA increased, ie, the number of anchoring groups was higher, thus inducing a more compact DPA-HA layer.

\section{Cell growth and viability}

In order to evaluate the acute toxicity of DPA-HA-coated $\gamma-\mathrm{Fe}_{2} \mathrm{O}_{3}$ nanoparticles, the growth and viability of labeled rat MSCs were examined. Unlabeled rat MSCs doubled their population within 48 hours, while cells labeled with coated nanoparticles grew slightly slower $(70 \%-100 \%$ of control). The slowest growth $(54 \% \pm 4 \%)$ was observed in cells labeled 


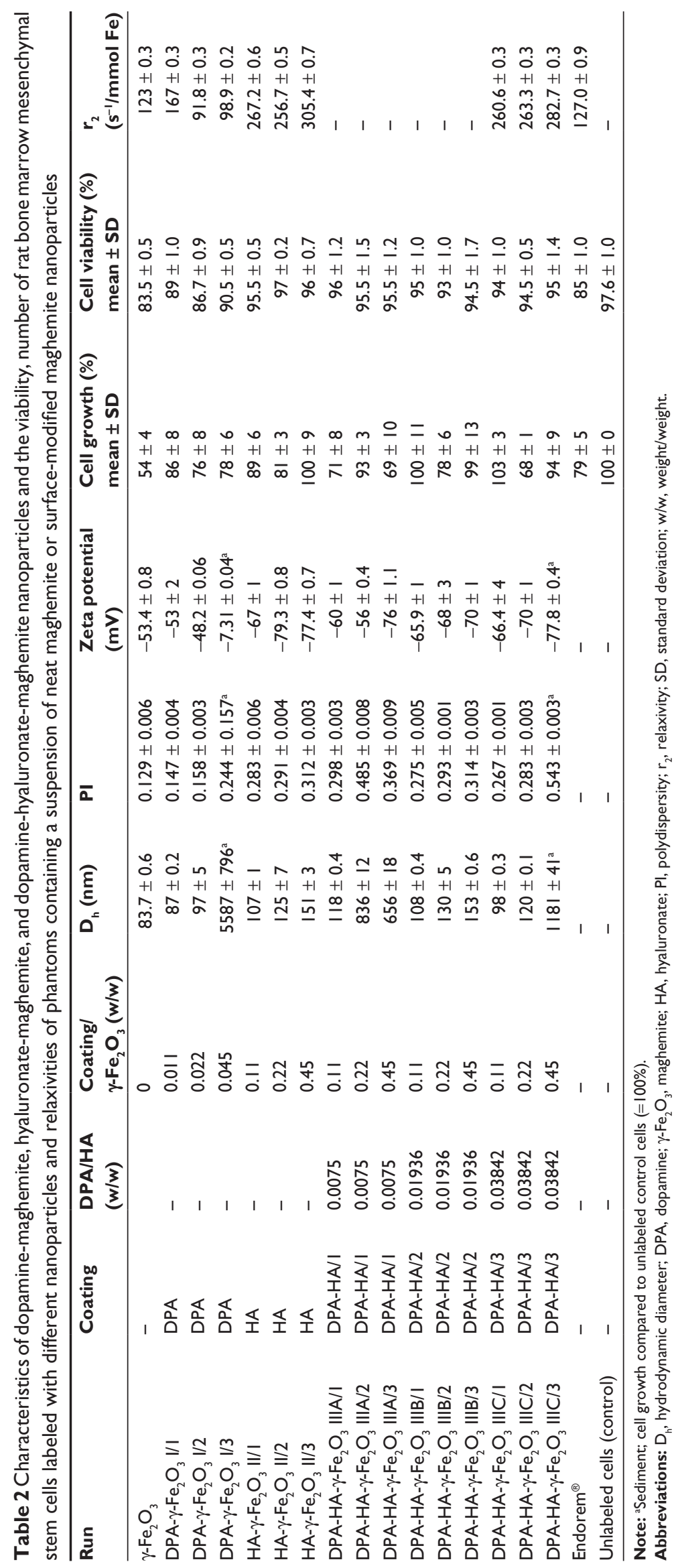


with uncoated $\gamma-\mathrm{Fe}_{2} \mathrm{O}_{3}$ nanoparticles. The viability of rat MSCs was tested using the trypan blue exclusion test. Varying the composition of the coating and increasing the concentration of DPA-HA did not substantially influence rat MSC viability (Table 2). A small decrease in viability $(83.5 \% \pm 0.5 \%)$ was observed in cells labeled with uncoated $\gamma$ - $\mathrm{Fe}_{2} \mathrm{O}_{3}$ nanoparticles. The viability of Endorem-labeled rat MSCs, considered the gold standard among commercial contrast agents used for cell labeling, reached about $85 \%$. These results are comparable with those from previous studies. ${ }^{30}$ When labeling chondrocytes, differences in growth and viability between labeled and unlabeled cells were not observed.

\section{Cell labeling efficiency}

The uptake of nanoparticles into rat MSCs (expressed as the percentage of labeled cells) was investigated using Prussian Blue staining. The cells were evaluated as to whether they were stained or not; the intensity of staining was not considered. In each group (Runs I, II, III), the highest percentage of labeled cells was obtained with nanoparticles containing the highest DPA concentration (Figure 4). Over $90 \%$ labeled cells was achieved with DPA-HA- $\gamma-\mathrm{Fe}_{2} \mathrm{O}_{3}$ nanoparticles Run IIIC/3 and DPA- $\gamma-\mathrm{Fe}_{2} \mathrm{O}_{3}$ nanoparticles Run $\mathrm{I} / 3$. However, the latter particles formed clumps and also adhered to the cell surface and the bottom of the culture well.
A labeling efficiency superior to that obtained with the commercial contrast agent Endorem (66\%) was also achieved with nanoparticles Run IIIA/3 (74\%) and I/2 (76\%). A labeling efficiency less than that obtained with Endorem was observed with uncoated $\gamma-\mathrm{Fe}_{2} \mathrm{O}_{3}(56 \%)$ and nanoparticles Run IIIA/1 (35\%), Run IIIA/2 (18\%), and Run IIIB/2 (52\%). The remainder of the nanoparticles gave results comparable with Endorem within the range of $61 \%-71 \%$.

To compare how much label was taken into the cells, the distribution of the intensity of Prussian Blue staining inside the labeled cells was studied (Figure 5). The highest intensity of Prussian Blue staining was detected in cells labeled with DPA-HA- $\gamma-\mathrm{Fe}_{2} \mathrm{O}_{3}$ nanoparticles Run IIIC/3. Similar results were obtained with DPA- $\gamma-\mathrm{Fe}_{2} \mathrm{O}_{3}$ Run I/3; however, these particles adhered to the cell surface and are therefore not shown in Figure 5. There were no marked differences among the rest of the coated nanoparticles, and a representative curve (Run II/3) is presented in Figure 5. The lowest intensity of Prussian Blue staining was observed in cells labeled with Endorem (Figure 5) or neat $\gamma$ - $\mathrm{Fe}_{2} \mathrm{O}_{3}$ (not shown).

Representative histological images of Prussian Blue staining are shown in Figure 6. They underline the results described in Figures 4 and 5. It was obvious that the bulky, negativelycharged HA molecule was internalized in cells less efficiently than positively-charged poly(L-lysine)-coated nanoparticles.

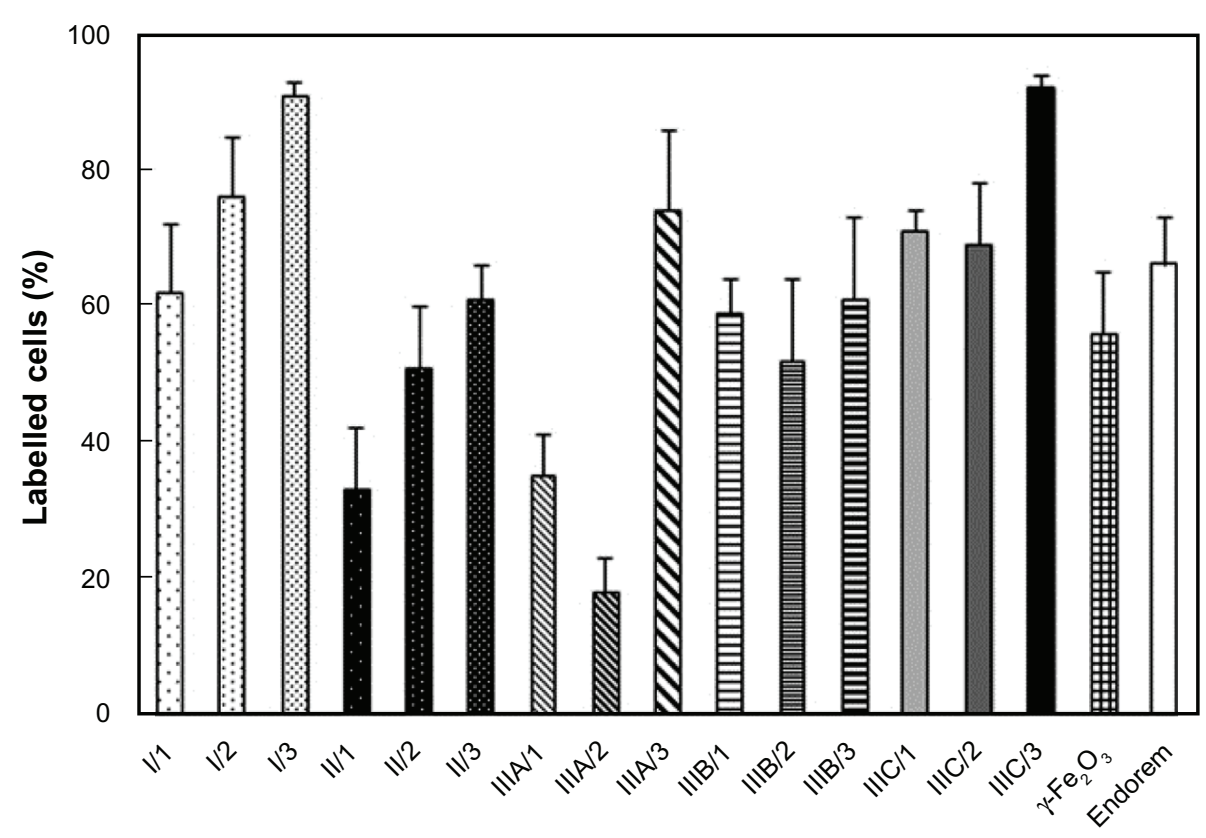

Figure 4 Labeling efficiency is expressed as the percentage of rat bone marrow mesenchymal stem cells labeled with hyaluronate-maghemite nanoparticles Runs II/I-3, dopamine-maghemite nanoparticles Runs $\mathrm{I} / \mathrm{I}-3$, dopamine-hyaluronate-maghemite nanoparticles Runs IIIA/I-3, IIIB/I-3, and IIIC/I-3, neat maghemite, and Endorem ${ }^{\circledR}$ (Guerbet, Roissy, France).

Notes: A colloid containing $15.4 \mu \mathrm{g}$ of iron per $\mathrm{mL}$ was added to the culture media for 72 hours. All experiments were done in triplicate, counting five optical fields from each well $(n=15)$.

Abbreviation: $\gamma-\mathrm{Fe}_{2} \mathrm{O}_{3}$, maghemite. 


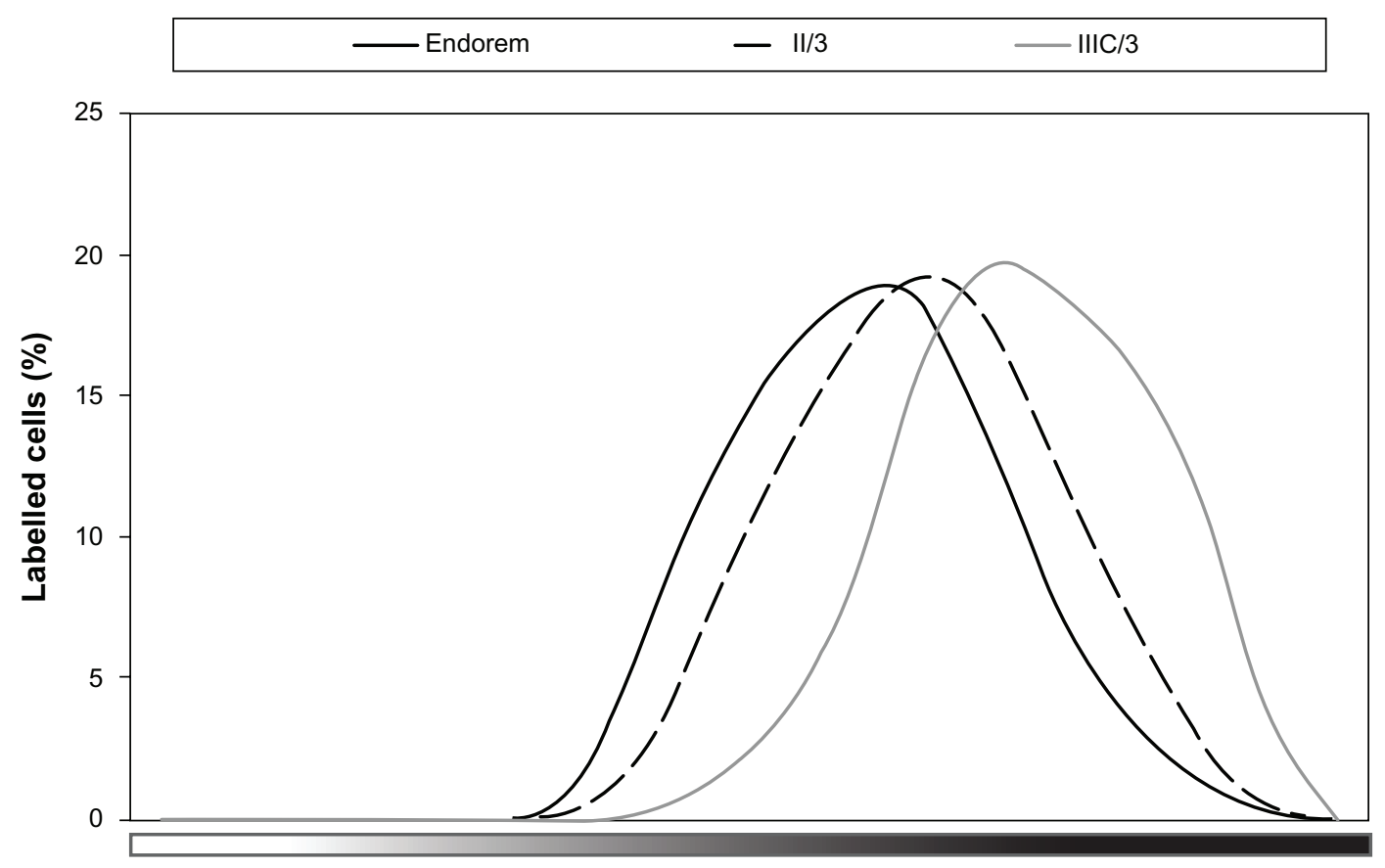

Figure 5 In the MATLAB ${ }^{\circledR} 6.0$ Image Processing Toolbox ${ }^{\mathrm{TM}}$ (MathWorks, Natick, MA), the color scale of Prussian Blue staining was precomputed from unstained and maximally stained nanoparticles (without cells) in CIE L*a*b color space and experimentally validated on images with stained cells.

Notes: The cells in each image were manually labeled, and for each cell the staining intensity as an index on the precomputed color scale was averaged. As a result, the figure shows representative curves of the distribution of the intensity of Prussian Blue staining ( $X$ axis) of rat bone marrow mesenchymal stem cells labeled with dopaminehyaluronate-maghemite nanoparticles Run IIIC/3, hyaluronate-maghemite nanoparticles Run II/3, and Endorem ${ }^{\circledR}$ (Guerbet, Roissy, France). The $\mathrm{Y}$ axis shows the percentage of cells for each labeling intensity.

$\mathrm{HA}-\gamma-\mathrm{Fe}_{2} \mathrm{O}_{3}$ nanoparticles exhibited a low cellular uptake, presumably because of HA desorption (Figure 6B). Only $\mathrm{HA}-\gamma-\mathrm{Fe}_{2} \mathrm{O}_{3}$ nanoparticles Run II/3 (Figure 6C), containing the highest concentration of HA, were comparable with Endorem (Figure 6G) or neat $\gamma-\mathrm{Fe}_{2} \mathrm{O}_{3}$ (Figure $6 \mathrm{H}$ ). The fact that DPA, which induces the adsorption of serum proteins, played an important role in cell internalization was confirmed by microscopic observation of Prussian Blue-stained rat MSCs labeled with DPA- $\gamma-\mathrm{Fe}_{2} \mathrm{O}_{3}$ nanoparticles (Figure 6A). DPA renders $\gamma$ - $\mathrm{Fe}_{2} \mathrm{O}_{3}$ nanoparticles with positive charges, which is desirable, while at the same time maintaining a small size favorable for internalization by the cells. It can be supposed that the more DPA on the particles, the greater the aggregation with proteins in the culture medium. Such aggregates are too large to be internalized by the cells. At a high concentration of DPA (Run I/3), the particles already stuck to the cell membranes and to the well bottom. Therefore, the highest concentration that could be safely used for cell labeling was that used in Run I/2. In contrast, HA acts as a steric barrier (protective shell) minimizing nanoparticle aggregation. Figure $6 \mathrm{D}-\mathrm{F}$ nicely document the synergistic effect of HA and DPA. In the group including DPA-HA- $\gamma-\mathrm{Fe}_{2} \mathrm{O}_{3}$ nanoparticles Run IIIC, the efficiency as well as the intensity of the cell labeling increased with increasing DPA concentration.
Superior results were obtained with the labeling of human chondrocytes (Figure 7A). From each group only Runs II/3, $\mathrm{IIIB} / 3$, and IIIC/3 were tested, since these nanoparticles performed best in rat MSC labeling. All tested nanoparticles achieved a labeling efficiency over $90 \%$; the highest labeling intensity was obtained with DPA-HA- $\gamma-\mathrm{Fe}_{2} \mathrm{O}_{3}$ nanoparticles Run IIIC/3, followed by HA- $\gamma-\mathrm{Fe}_{2} \mathrm{O}_{3}$ Run II/3 and DPA-HA$\gamma-\mathrm{Fe}_{2} \mathrm{O}_{3}$ Run IIIB/3. Similar results were obtained in the distribution of the intensity of Prussian Blue staining (Figure 7B). In contrast to the results obtained in rat MSCs, $\mathrm{HA}-\gamma-\mathrm{Fe}_{2} \mathrm{O}_{3}$ nanoparticles Run II/3 showed a higher labeling efficiency, as well as staining intensity, than DPA-HA- $\gamma-\mathrm{Fe}_{2} \mathrm{O}_{3}$ nanoparticles Run IIIB/3. Histological images (Figure 8) clearly support the data shown in Figure 7. In contrast to the results observed in rat MSCs, DPA-HA- $\gamma-\mathrm{Fe}_{2} \mathrm{O}_{3}$ nanoparticles Run IIIC/3 already aggregated and also adhered to the cell surface (Figure 8D). As MSCs and chondrocytes possess receptors for HA (CD44), iron oxide uptake is therefore most likely a receptor-mediated process.

\section{Cell differentiation into chondrogenic phenotypes}

For the use of stem cells in cell therapies, their ability to differentiate in the presence of superparamagnetic 
A

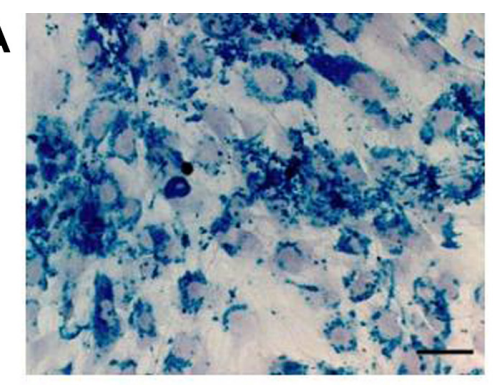

C

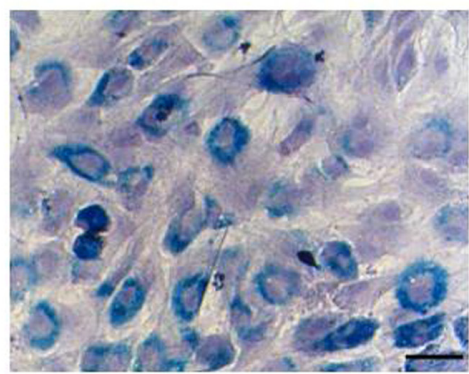

E

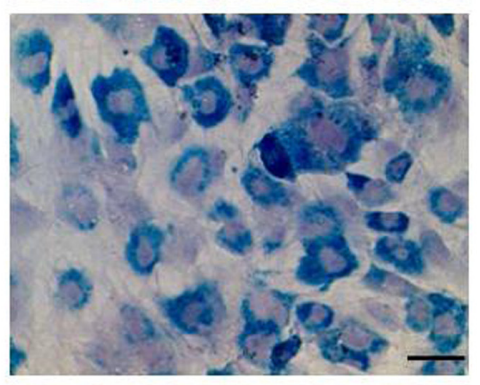

G

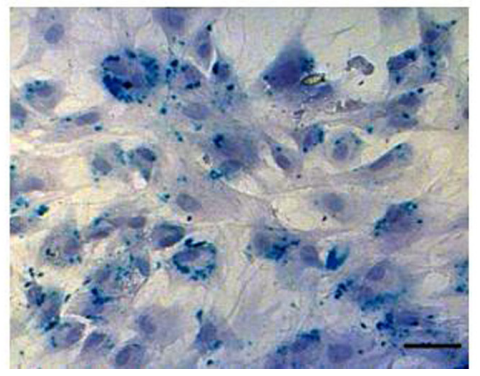

B

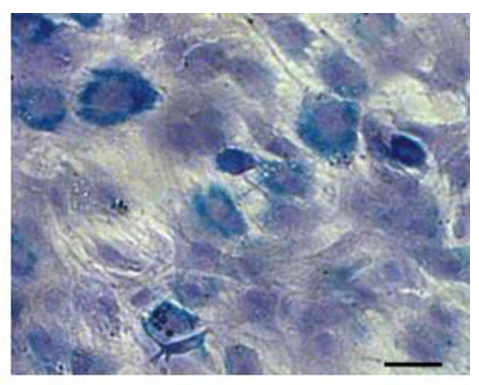

D

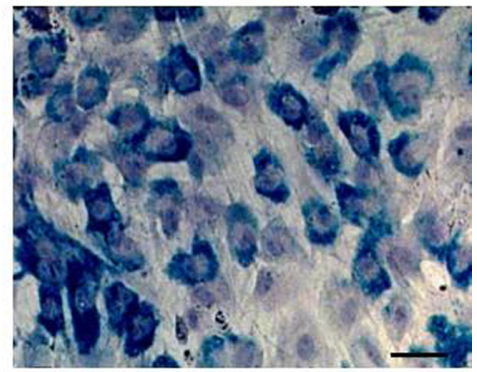

F

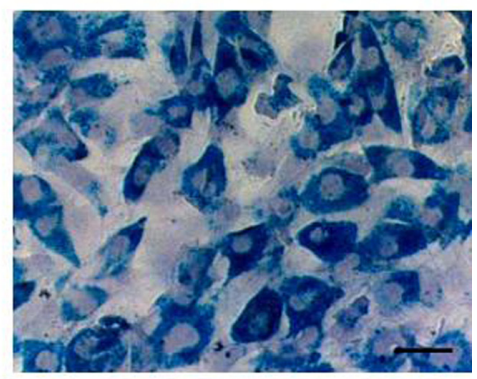

$\mathrm{H}$

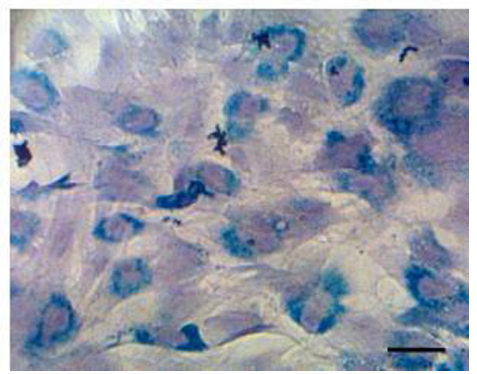

Figure 6 Microscopic observation of Prussian Blue-stained rat bone marrow mesenchymal stem cells labeled with (A) dopamine-maghemite nanoparticles Run I/3, (B) hyaluronate-maghemite nanoparticles Run II/I and (C) Run II/3, dopamine-hyaluronate-maghemite nanoparticles (D) Run IIIC/I, (E) Run IIIC/2, and (F) Run IIIC/3, (G) Endorem ${ }^{\circledast}$ (Guerbet, Roissy, France), and $(\mathbf{H})$ neat maghemite.

Notes: Cell nuclei are counterstained with hematoxylin. Scale bar $25 \mu \mathrm{m}$.

nanoparticles is crucial. Although iron oxide nanoparticles are generally considered as safe, there are several reports in the literature that differently coated superparamagnetic iron oxide particles negatively affect the chondrogenic differentiation of MSCs. ${ }^{31,32}$ Some superparamagnetic iron oxides are suspected to produce reactive oxygen species ${ }^{33}$ or affect the cytoskeleton and cell membrane. ${ }^{34}$ Since HA is present in cartilage, the chondrogenic differentiation of rat MSCs labeled with $\mathrm{HA}-\gamma-\mathrm{Fe}_{2} \mathrm{O}_{3}$ nanoparticles Run II/3, DPA-HA- $\gamma-\mathrm{Fe}_{2} \mathrm{O}_{3}$ nanoparticles Run IIIC/3, and Endorem was tested. After 20 days of incubation in chondrogenic medium, the cells labeled with DPA-HA- $\gamma-\mathrm{Fe}_{2} \mathrm{O}_{3}$ nanoparticles Run
IIIC/3 and with Endorem formed solid chondrogenic pellets with positive Alcian Blue staining, confirming differentiation into chondrocytes (Figure 9A and C). In contrast, the cells labeled with $\mathrm{HA}-\gamma-\mathrm{Fe}_{2} \mathrm{O}_{3}$ nanoparticles Run II/3 were not able to form a proper pellet (Figure 9E) and no differentiation was observed. Prussian Blue staining confirmed that the labeled cells contained iron (Figure 9B-F). The amount of iron was apparently higher in cells and pellets containing DPA-HA- $\gamma$ $\mathrm{Fe}_{2} \mathrm{O}_{3}$ nanoparticles Run IIIC/3 and $\mathrm{HA}-\gamma-\mathrm{Fe}_{2} \mathrm{O}_{3}$ nanoparticles Run II/3 than in Endorem-labeled pellets, which corresponded to the higher labeling efficiency of these nanoparticles compared to Endorem. The results show that the chondrogenic 
A

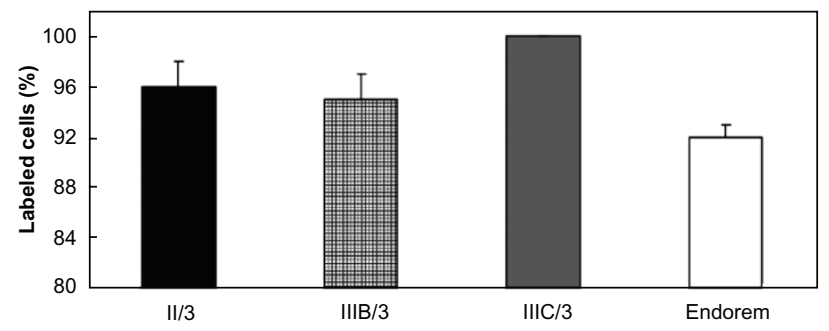

B

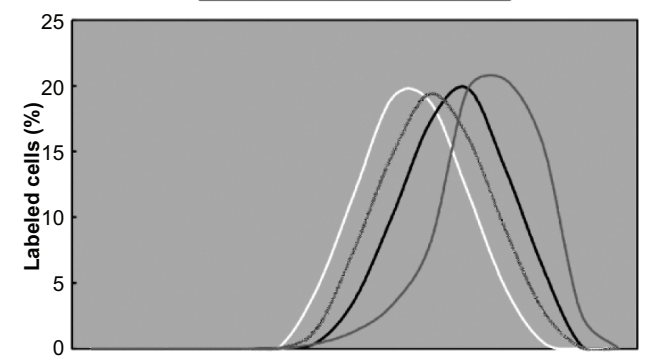

Figure 7 (A) Labeling efficiency of human chondrocytes expressed as the number of Prussian Blue-positive cells. (B) Distribution of Prussian Blue labeling intensity in human chondrocytes.

differentiation of MSCs could be impaired by HA- $\gamma-\mathrm{Fe}_{2} \mathrm{O}_{3}$ nanoparticles. The exact effect of HA on chondrogenic differentiation is not clear. $\mathrm{Ng}$ et al showed that exogenous HA of molecular weight $2.5 \times 10^{5} \mathrm{Da}$, when added to the culture medium of an explant culture of articular cartilage, inhibited both aggrecan and HA synthesis in a concentrationdependent manner. ${ }^{35}$ It can be speculated that residual bulky HA molecules remaining in the media or attached to the cell surface prevent pellet formation and thus impair chondrogenic differentiation. In contrast, the presence of DPA not only leads to a higher amount of label inside the cells, but also has no negative effect on pellet formation and subsequently on chondrogenic differentiation, most probably due to the better internalization of the nanoparticles inside the cells.

\section{MRI relaxometry}

Contrast in an MRI depends not only on the proton density of the measured object, but (in the case of $\mathrm{T}_{1}$-weighted or
A

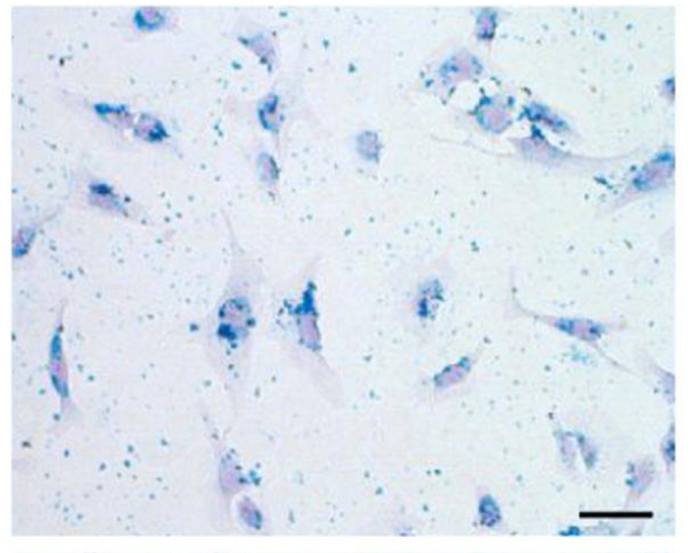

C

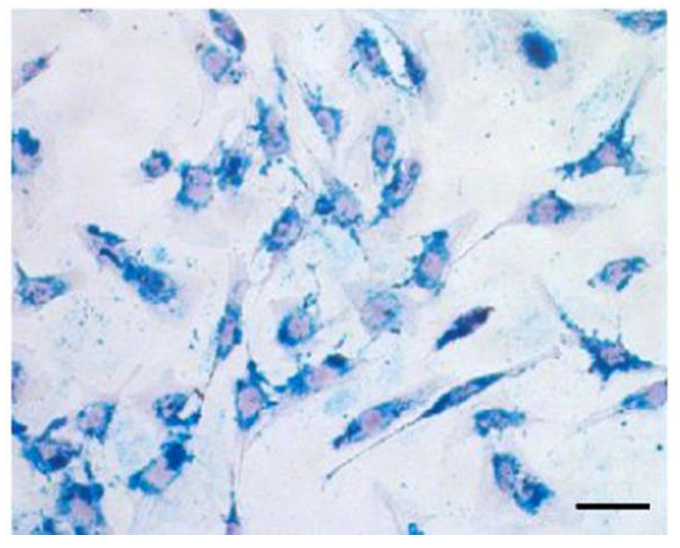

B

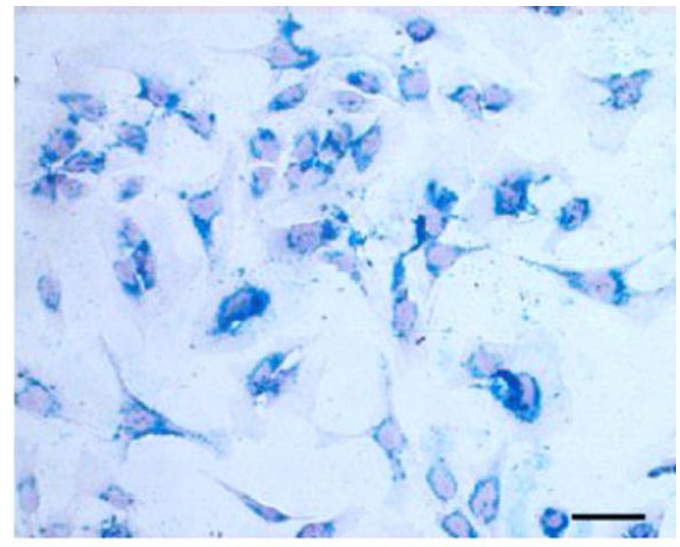

D

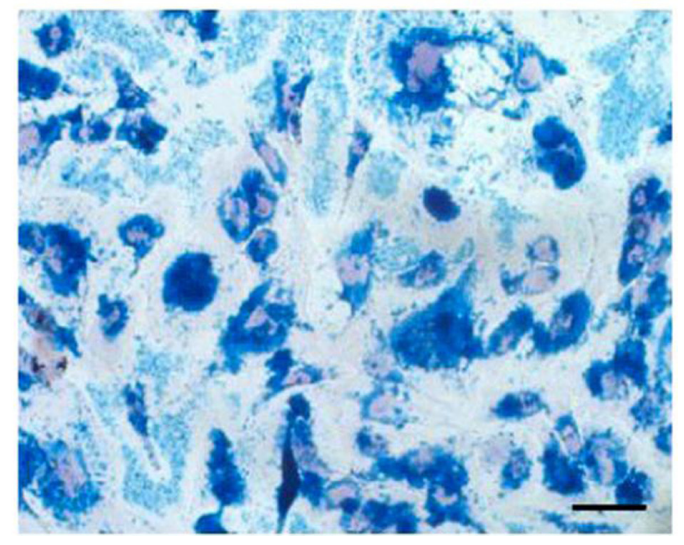

Figure 8 Prussian Blue staining of human chondrocytes labeled with (A) Endorem ${ }^{\circledast}$ (Guerbet, Roissy, France), (B) dopamine-hyaluronate-maghemite nanoparticles Run IIIB/3, (C) hyaluronate-maghemite nanoparticles Run II/3, and (D) dopamine-hyaluronate-maghemite nanoparticles Run IIIC/3.

Notes: Cell nuclei are counterstained with nuclear fast red. Scale bar $25 \mu \mathrm{m}$. 
A
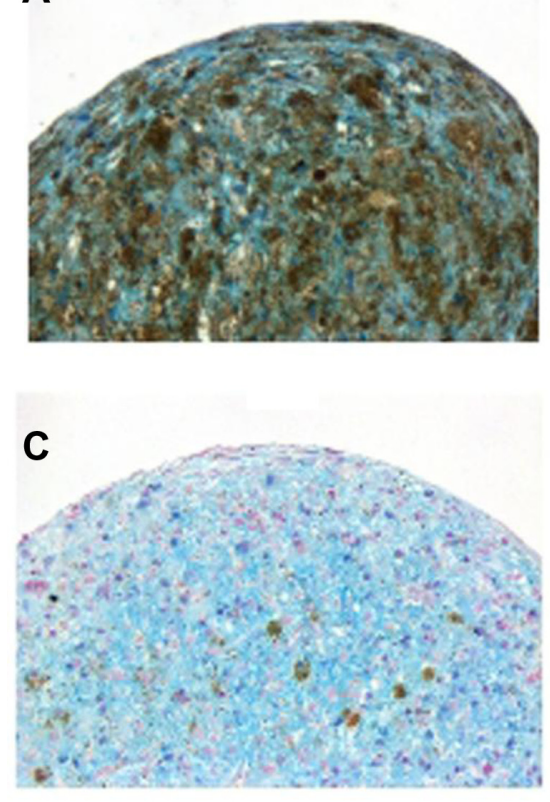

E

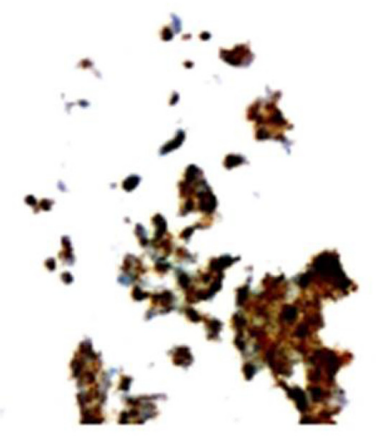

B
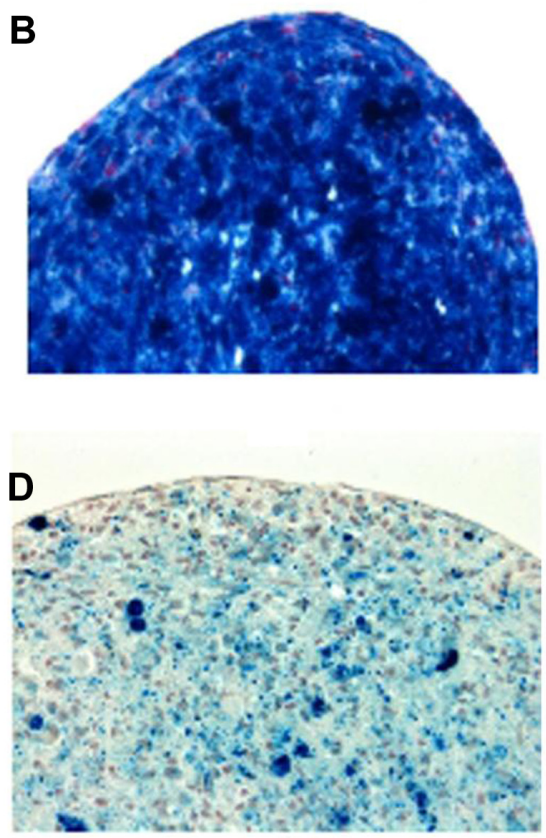

$\mathbf{F}$

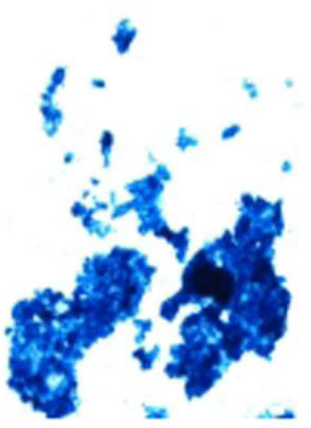

Figure 9 To determine whether hyaluronate molecules, which are also present in the cartilage extracellular matrix, can affect chondrogenic differentiation, rat bone marrow mesenchymal stem cells labeled with (A and B) dopamine-hyaluronate-maghemite nanoparticles Run IIIC/3, (C and D) Endorem ${ }^{\circledR}(\mathrm{Guerbet}, \mathrm{Roissy}$, France), and (E and $\mathbf{F}$ ) hyaluronate-maghemite nanoparticles Run II/3 were differentiated into a chondrogenic phenotype.

Notes: The left column shows staining for Alcian Blue (a marker of chondrogenic differentiation), while the right column represents Prussian Blue staining. Iron is visible as (A, $\mathbf{C}$ and $\mathbf{E})$ brown or (B, $\mathbf{D}$ and $\mathbf{F})$ blue deposits.

$\mathrm{T}_{2}$-weighted images) predominantly on relaxation times. Relaxometry enables the direct measurement of relaxivities (ie, the reciprocal values of relaxation times related to concentration), which reflect both the concentration of paramagnetic or superparamagnetic substances and water exchange, which also varies with the size and solubility of the given magnetic particles.

Table 2 summarizes the relaxivities of DPA $-\gamma-\mathrm{Fe}_{2} \mathrm{O}_{3}$, $\mathrm{HA}-\boldsymbol{\gamma}-\mathrm{Fe}_{2} \mathrm{O}_{3}$, and DPA-HA- $\gamma-\mathrm{Fe}_{2} \mathrm{O}_{3}$ nanoparticles. DPA$\gamma-\mathrm{Fe}_{2} \mathrm{O}_{3}$ nanoparticles obtained at a low DPA $\gamma-\mathrm{Fe}_{2} \mathrm{O}_{3}$ ratio (Run I/1) displayed a higher relaxivity than did neat $\gamma-\mathrm{Fe}_{2} \mathrm{O}_{3}$. At higher DPA $/ \gamma-\mathrm{Fe}_{2} \mathrm{O}_{3}$ ratios (Runs I/2 and I/3), relaxivity decreased. The authors speculate that a higher DPA $\gamma-\mathrm{Fe}_{2} \mathrm{O}_{3}$ ratio may lead to greater nanoparticle aggregation. During aggregation, contacts between the nanoparticles and water molecules are reduced due to the exclusion of water from the interior of the aggregates.

The relaxivity of $\mathrm{HA}-\gamma-\mathrm{Fe}_{2} \mathrm{O}_{3}$ nanoparticles (Group II) was substantially higher than that of DPA- $\gamma-\mathrm{Fe}_{2} \mathrm{O}_{3}$ nanoparticles and increased with an increasing $\mathrm{HA} / \gamma-\mathrm{Fe}_{2} \mathrm{O}_{3}$ ratio (Figure 10). The dependence approximately followed an exponential fit (solid line in Figure 10, calculated without the last point). The authors hypothesize that with an increasing $\mathrm{HA} / \gamma-\mathrm{Fe}_{2} \mathrm{O}_{3}$ ratio, the amount of water surrounding the particles increased due to the extremely high hydrophilicity of HA. HA carries large amounts of water molecules in the close vicinity of $\gamma-\mathrm{Fe}_{2} \mathrm{O}_{3}$ particles, thus increasing MRI contrast. However, at very high $\mathrm{HA} / \gamma-\mathrm{Fe}_{2} \mathrm{O}_{3}$ ratios $\left(\mathrm{HA} / \gamma-\mathrm{Fe}_{2} \mathrm{O}_{3} \sim 0.6\right.$ weight/weight and more), $\mathrm{HA}-\gamma-\mathrm{Fe}_{2} \mathrm{O}_{3}$ nanoparticles sedimented and relaxivity decreased (last point in Figure 10). 


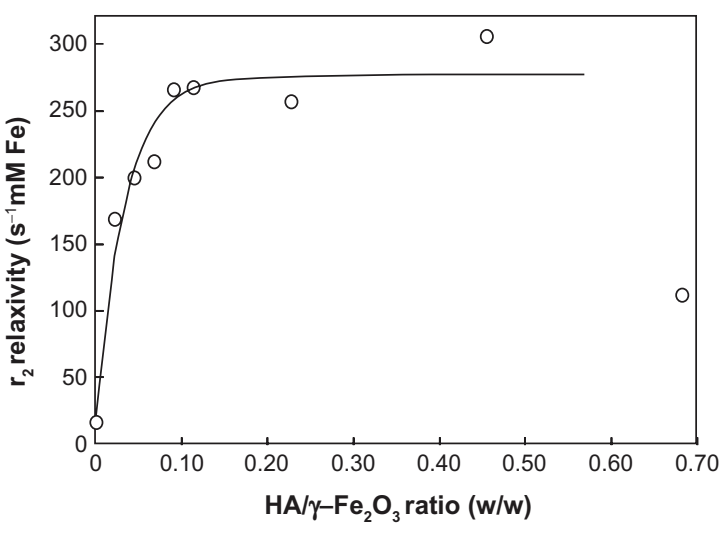

Figure 10 Dependence of the relaxivity of hyaluronate-maghemite nanoparticles Group II on the hyaluronate/maghemite ratio.

Note: The solid line represents an exponential fit.

Abbreviations: Fe, iron; $\mathrm{HA}$, hyaluronate; $\gamma-\mathrm{Fe}_{2} \mathrm{O}_{3}$, maghemite; $r_{2}$, relaxivity.

DPA-HA- $\gamma-\mathrm{Fe}_{2} \mathrm{O}_{3}$ nanoparticles revealed a similar relaxivity as did $\mathrm{HA}-\gamma-\mathrm{Fe}_{2} \mathrm{O}_{3}$ nanoparticles, ie, relaxivity was substantially higher than in nanoparticles associated with DPA only. This confirmed the importance of HA for ensuring the stability of the colloid and for water exchange, which plays a crucial role in water relaxation.

The relaxation rates of gelatin containing suspensions of labeled cells and measured at 0.5 and $4.7 \mathrm{~T}$ are shown in Table 3. The relaxation rates of the cell suspensions depended not only on the relaxivity of the nanoparticles used for cell labeling, but mainly on the number of particles internalized by the cells. Although $\mathrm{HA}-\gamma-\mathrm{Fe}_{2} \mathrm{O}_{3}$ nanoparticles exhibited the highest relaxivities (because HA ensured colloidal stability and excellent water exchange), the highest relaxation rate was found in cells labeled with DPA-HA- $\gamma-\mathrm{Fe}_{2} \mathrm{O}_{3}$ nanoparticles at a DPA/HA ratio $=0.01936$ (weight/weight) (Table 3). It could thus be hypothesized that DPA associated at a moderate concentration substantially improved cellular uptake.

Nevertheless, at a higher DPA/HA ratio $(0.03842$ weight/weight), relaxivity again decreased, probably due to aggregation leading to sedimentation, which lowered both the relaxivity of the nanoparticles and also the cellular uptake of the particles.

Table 3 Relaxation rates of rat bone marrow mesenchymal stem cells labeled with surface-modified maghemite nanoparticles

\begin{tabular}{|c|c|c|}
\hline & $\begin{array}{l}R_{2}\left(s^{-1} / 10^{6}\right. \\
r M S C s / m L) \\
\text { at } 0.5 \mathrm{~T}\end{array}$ & $\begin{array}{l}R_{2}\left(\mathrm{~s}^{-1} / 10^{6}\right. \\
\mathrm{rMSCs} / \mathrm{mL}) \\
\text { at } 4.7 \mathrm{~T}\end{array}$ \\
\hline $\mathrm{HA}-\gamma-\mathrm{Fe}_{2} \mathrm{O}_{3} \mathrm{II} / 3$ & $3.7 \pm 0.4$ & $7.8 \pm 0.3$ \\
\hline DPA-HA- $\gamma-\mathrm{Fe}_{2} \mathrm{O}_{3} \mathrm{IIIB} / 3$ & $6.7 \pm 0.1$ & $11.6 \pm 0.8$ \\
\hline DPA-HA- $\gamma-\mathrm{Fe}_{2} \mathrm{O}_{3} \mathrm{IIIC} / 3$ & $3.3 \pm 0.3$ & $5.8 \pm 1.0$ \\
\hline
\end{tabular}

Abbreviations: DPA, dopamine; $\gamma-\mathrm{Fe}_{2} \mathrm{O}_{3}$, maghemite; $\mathrm{HA}$, hyaluronate; $\mathrm{R}_{2}$, relaxation rates; $r M S C s$, rat bone marrow mesenchymal stem cells.

\section{Conclusion}

The surface properties of $\gamma-\mathrm{Fe}_{2} \mathrm{O}_{3}$ nanoparticles play a key role in their permeation through the cell membrane. HA was therefore associated with a DPA anchoring group and the resulting coating was used for the efficient surface modification of $\gamma-\mathrm{Fe}_{2} \mathrm{O}_{3}$ nanoparticles. While the DPA moiety had a high affinity for the $\gamma-\mathrm{Fe}_{2} \mathrm{O}_{3}$ surface, because the catechol groups of DPA formed stable chemical bonds on the iron oxide surface, HA ensured colloidal stability and boosted the relaxivity of the iron oxide. Surface-modified magnetic nanoparticles were used for rat MSC and chondrocyte labeling. Even though $\gamma-\mathrm{Fe}_{2} \mathrm{O}_{3}$ nanoparticles coated with DPA alone penetrated into the cells due to the positive DPA charge, the best results were obtained with the formation of a DPA-HA ionic associate on the particles. Viability assays revealed no significant differences in either the proliferation or viability of cells labeled with DPA$\mathrm{HA}-\gamma-\mathrm{Fe}_{2} \mathrm{O}_{3}$ nanoparticles compared to unlabeled cells. A low concentration of DPA-HA- $\gamma-\mathrm{Fe}_{2} \mathrm{O}_{3}$ nanoparticles was sufficient to achieve clearly visible contrast in MRI. DPA was involved in the internalization of the nanoparticles by the cells, and its concentration was important to achieve good cell labeling. The presence of HA on the surface of the nanoparticles may mediate their penetration into cells via the cell membrane and facilitate their uptake by MSCs. The percentage of Prussian Blue-stained cells was highest $(85 \%)$ in cells labeled with DPA-HA- $\gamma-\mathrm{Fe}_{2} \mathrm{O}_{3}$ nanoparticles Run IIIC/3. Thus, the association of DPA to the HA chain and the subsequent anchoring of DPA-HA on the $\gamma-\mathrm{Fe}_{2} \mathrm{O}_{3}$ surface via hydroxyl groups played a pivotal role in cellular uptake and MRI. Similarly, the chondrogenic differentiation of labeled cells was successfully achieved only with DPA-HA$\gamma-\mathrm{Fe}_{2} \mathrm{O}_{3}$ nanoparticles. The advantage of DPA-HA- $\gamma-\mathrm{Fe}_{2} \mathrm{O}_{3}$ nanoparticles consists in the availability of a large number of carboxyl groups for the prospective attachment of target molecules, antibodies, proteins, fluorescent labels, therapeutic agents (growth hormones), or cancerostatics. At the same time, MRI can detect the labeled cells, thus enabling their tracking in the tissue, which is important in applications such as cell imaging, cell tracking, cell-based therapies, and tissue engineering. Such nanoparticles might also be useful for the labeling of neurons, glial cells, or cartilage.

\section{Acknowledgments}

The financial support of the Grant Agency of the Czech Republic (grant 203/09/1242, P207/12/J013, and P304/12/1370), the European Commission (DiaTools project no 259796) and the Center for Cell Therapy and Tissue Repair (No 1M0538) is 
gratefully acknowledged. The authors thank James Dutt for critical reading of the manuscript.

\section{Disclosure}

The authors report no conflicts of interest in this work.

\section{References}

1. Horak D, Babic M, Mackova H, Benes MJ. Preparation and properties of magnetic nano- and microsized particles for biological and environmental separations. J Sep Sci. 2007;30(11):1751-1772.

2. Tanase M, Felton EJ, Gray DS, Hultgren A, Chen CS, Reich DH. Assembly of multicellular constructs and microarrays of cells using magnetic nanowires. Lab Chip. 2005;5(6):598-605.

3. Bulte JW, Zhang S, van Gelderen P, et al. Neurotransplantation of magnetically labeled oligodendrocyte progenitors: magnetic resonance tracking of cell migration and myelination. Proc Natl Acad Sci USA. 1999;96(26):15256-15261.

4. Arbab AS, Jordan EK, Wilson LB, Yocum GT, Lewis BK, Frank JA. In vivo trafficking and targeted drug delivery of magnetically labeled stem cells. Hum Gene Ther. 2004;15(4):351-360.

5. Muthana M, Scott SD, Farrow N, et al. A novel magnetic approach to enhance the efficacy of cell-based gene therapies. Gene Ther. 2008; 15(12):902-910.

6. Gaihre B, Khil MS, Kang HK, Kim HY. Bioactivity of gelatin coated magnetic iron oxide nanoparticles: in vitro evaluation. J Mater Sci Mater Med. 2009;20(2):573-581.

7. Lewin M, Carlesso N, Tung CH, et al. Tat peptide-derivatized magnetic nanoparticles allow in vivo tracking and recovery of progenitor cells. Nat Biotechnol. 2000;18(4):410-414.

8. Josephson L, Tung CH, Moore A, Weissleder R. High-efficiency intracellular magnetic labeling with novel superparamagnetic-Tat peptide conjugates. Bioconjug Chem. 1999;10(2):186-191.

9. Bulte JW, Douglas T, Witwer B, et al. Magnetodendrimers allow endosomal magnetic labeling and in vivo tracking of stem cells. Nat Biotechnol. 2001;19(12):1141-1147.

10. Babic M, Horak D, Trchova M, et al. Poly(L-lysine)-modified iron oxide nanoparticles for stem cell labeling. Bioconjug Chem. 2008;19(3): 740-750.

11. Frank JA, Miller BR, Arbab AS, et al. Clinically applicable labeling of mammalian and stem cells by combining superparamagnetic iron oxides and transfection agents. Radiology. 2003;228(2):480-487.

12. Terrovitis JV, Bulte JW, Sarvananthan S, et al. Magnetic resonance imaging of ferumoxide-labeled mesenchymal stem cells seeded on collagen scaffolds - relevance to tissue engineering. Tissue Eng. 2006; 12(10):2765-2775.

13. Ju S, Teng G, Zhang Y, Ma M, Chen F, Ni Y. In vitro labeling and MRI of mesenchymal stem cells from human umbilical cord blood. Magn Reson Imaging. 2006;24(5):611-617.

14. Park BH, Jung JC, Lee GH, et al. Comparison of labeling efficiency of different magnetic nanoparticles into stem cell. Colloid Surf A Physicochem Eng Asp. 2008;313-314:145-149.

15. Zhu AP, Fang N, Chan-Park MB, Chan V. Interaction between O-carboxymethylchitosan and dipalmitoyl-sn-glycero-3-phosphocholine bilayer. Biomaterials. 2005;26(34):6873-6879.
16. Kuo JW. Practical Aspects of Hyaluronan Based Medical Products. Boca Raton: Taylor \& Francis, 2006.

17. Kawaguchi H. Functional polymer microspheres. Prog Polym Sci. 2000; 25(8):1171-1210

18. Lee Y, Lee H, Kim YB, et al. Bioinspired surface immobilization of hyaluronic acid on monodisperse magnetite nanocrystals for targeted cancer imaging. Adv Mater. 2008;20(21):4154-4157.

19. Lim EK, Kim HO, Jang E, et al. Hyaluronan-modified magnetic nanoclusters for detection of CD44-overexpressing breast cancer by MR imaging. Biomaterials. 2011;32(31):7941-7950.

20. Stern R, Asari AA, Sugahara KN. Hyaluronan fragments: an information-rich system. Eur J Cell Biol. 2006;85(8):699-715.

21. Prevo R, Banerji S, Ferguson DJ, Clasper S, Jackson DG. Mouse LYVE-1 is an endocytic receptor for hyaluronan in lymphatic endothelium. J Biol Chem. 2001;276(22):19420-19430.

22. Lee H, Lee BP, Messersmith PB. A reversible wet/dry adhesive inspired by mussels and geckos. Nature. 2007;448(7151):338-341.

23. Horak D, Babic M, Jendelova P, et al. D-mannose-modified iron oxide nanoparticles for stem cell labeling. Bioconjug Chem. 2007;18(3): 635-644.

24. Zaveta K, Lancok A, Marysko M, Pollert E, Horak D. Superparamagnetic properties of $\gamma-\mathrm{Fe}_{2} \mathrm{O}_{3}$ particles: Mossbauer spectroscopy and DC magnetic measurement. Czech J Phys. 2006;56 Suppl 3:E83-E91.

25. Choi KY, Lee S, Park K, et al. Preparation and characterization of hyaluronic acid-based hydrogel nanoparticles. J Phys Chem Solids. 2008;69(5-6):1591-1595

26. Darr A, Calabro A. Synthesis and characterization of tyramine-based hyaluronan hydrogels. J Mater Sci Mater Med. 2009;20(1):33-44.

27. $\mathrm{Xu} \mathrm{C}, \mathrm{Xu} \mathrm{K}, \mathrm{Gu} \mathrm{H}$, et al. Dopamine as a robust anchor to immobilize functional molecules on the iron oxide shell of magnetic nanoparticles. J Am Chem Soc. 2004;126(32):9938-9939.

28. Basti H, Ben Tahar L, Smiri LS, et al. Catechol derivatives-coated $\mathrm{Fe}_{3} \mathrm{O}_{4}$ and $\gamma-\mathrm{Fe}_{2} \mathrm{O}_{3}$ nanoparticles as potential MRI contrast agents. $J$ Colloid Interface Sci. 2010;341(2):248-254.

29. Rajh T, Chen LX, Lukas K, Liu T, Thurnauer MC, Tiede DM. Surface restructuring of nanoparticles: an efficient route for ligand-metal oxide crosstalk. J Phys Chem B. 2002;106(41):10543-10552.

30. Babic M, Horak D, Jendelova P, et al. Poly(N,N-dimethylacrylamide)coated maghemite nanoparticles for stem cell labeling. Bioconjug Chem. 2009;20(2):283-294.

31. Henning TD, Sutton EJ, Kim A, et al. The influence of ferucarbotran on the chondrogenesis of human mesenchymal stem cells. Contrast Media Mol Imaging. 2009;4(4):165-173.

32. Farrell E, Wielopolski P, Pavljasevic P, et al. Effects of iron oxide incorporation for long term cell tracking on MSC differentiation in vitro and in vivo. Biochem Biophys Res Commun. 2008;369(4): 1076-1081.

33. Emerit J, Beaumont C, Trivin F. Iron metabolism, free radicals, and oxidative injury. Biomed Pharmacother. 2001;55(6):333-339.

34. Berry CC, Wells S, Charles S, Aitchison G, Curtis AS. Cell response to dextran-derivatised iron oxide nanoparticles post internalization. Biomaterials. 2004;25(23):5405-5413.

35. Ng CK, Handley CJ, Preston BN, Robinson HC, Bolis S, Parker G. Effect of exogenous hyaluronan and hyaluronan oligosaccharides on hyaluronan and aggrecan synthesis and catabolism in adult articular cartilage explants. Arch Biochem Biophys. 1995;316(1):596-606.
International Journal of Nanomedicine

\section{Publish your work in this journal}

The International Journal of Nanomedicine is an international, peerreviewed journal focusing on the application of nanotechnology in diagnostics, therapeutics, and drug delivery systems throughout the biomedical field. This journal is indexed on PubMed Central, MedLine, CAS, SciSearch $\AA$, Current Contents ${ }^{\circledR} /$ Clinical Medicine,

\section{Dovepress}

Journal Citation Reports/Science Edition, EMBase, Scopus and the Elsevier Bibliographic databases. The manuscript management system is completely online and includes a very quick and fair peer-review system, which is all easy to use. Visit http://www.dovepress.com/ testimonials.php to read real quotes from published authors. 